\title{
Turbine Map Extension - Theoretical Considerations and Practical Advice
}

\section{Original article}

Article history:

Submission date: 24 September 2020

Acceptance date: 13 October 2020

Publication date: 26 November 2020

This is the updated version of a paper originally presented at the Global Power and Propulsion Virtual Technical

Conference, GPPS Chania20, Sept. 7-9 2020.

\section{Check for updates}

*Correspondence:

JK: kurzke@gasturb.de

\section{Peer review:}

Single blind

\section{Copyright:}

(ㄷ) 2020 Kurzke () This is an open access article distributed under the Creative Commons Attribution Non Commercial License (CC BY-NC 4.0), which permits unrestricted use, distribution, and reproduction in any medium for noncommercial purposes only, provided the original work is properly cited and its authors credited.

\section{Keywords:}

Turbine Map; Turbojet; turbofan; Starting; Windmilling

\section{Citation:}

Kurzke J. (2020). Turbine Map Extension Theoretical Considerations and Practical Advice. Journal of the Global Power and Propulsion Society. 4: 176-189. https://doi.org/10.33737/jgpps/128465
Joachim Kurzke $e^{1, *}$

${ }^{1}$ Gasturb Performance Consulting, Dachau, Germany

\begin{abstract}
Physically sound compressor and turbine maps are the key to accurate aircraft engine performance simulations. Usually, maps only cover the speed range between idle and full power. Simulation of starting, windmilling and re-light requires maps with sub-idle speeds as well as pressure ratios less than unity. Engineers outside industry, universities and research facilities may not have access to the measured rig data or the geometrical data needed for CFD calculations.

Whilst research has been made into low speed behavior of turbines, little has been published and no advice is available on how to extrapolate maps. Incompressible theory helps with the extrapolation down to zero flow as in this region the Mach numbers are low. The zero-mass flow limit plays a special role; its shape follows from turbine velocity triangle analysis.

Another helpful correlation is how mass flow at a pressure ratio of unity changes with speed. The consideration of velocity triangles together with the enthalpy-entropy diagram leads to the conclusion that in these circumstances flow increases linearly with speed.

In the incompressible flow region, a linear relationship exists between torque/flow and flow. The slope is independent of speed and can be found from the speed lines for which data are available. This knowledge helps in extending turbine maps into the regions where pressure ratio is less than unity.

The application of the map extension method is demonstrated with an example of a three-stage low pressure turbine designed for a business jet engine.
\end{abstract}

\section{Introduction}

In by far the biggest area of a turbine map both the stator exit Mach number and the rotor exit Mach number (in the relative system) are high. In this map region the similarity laws for incompressible flow are of little value for extrapolation purposes. However, for extending a turbine map to the low mass flow region - where turbines operate in a windmilling engine - correlations derived from incompressible flow theory are very helpful.

\section{Theory}

\section{Work and flow coefficient}

If we consider the form of the $\psi-\Phi$ relationship for a single stage turbine with symmetrical velocity triangles in simple terms, we can conclude that the work coefficient $\psi$ is a linear function of the flow coefficient $\Phi$. This follows from the fact that the flow leaves a blade or vane row in the direction given by the trailing edge geometry (see Figure 1). 


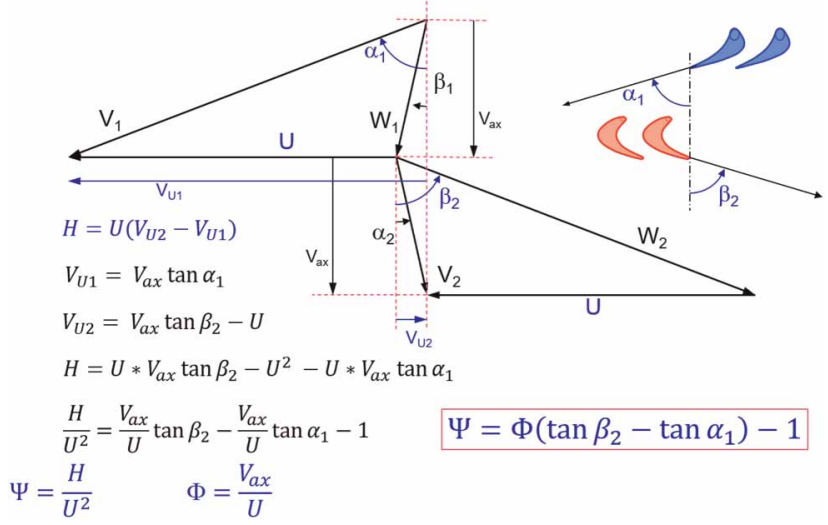

Figure 1. Turbine work and flow coefficient.

The work output $\mathrm{H}$ is a straight line when plotted as $\Psi$ over $\Phi$, whereas work input $\mathrm{H}_{\mathrm{is}}$ - calculated from pressure ratio - is not (see Figure 2).

$$
\psi=\Phi *\left(\tan \beta_{2}-\tan \alpha_{1}\right)-1=c_{1} * \Phi-1
$$

The losses in the expansion process, described by efficiency $\eta=H / H_{i s}$, are smallest at the peak efficiency point.

The only prerequisite for the validity of Equation 1 is that the (relative) flow direction downstream of the blades and vanes is enforced by the geometry of the blades and vanes. Furthermore, in an incompressible fluid (constant density), there is only one curve for $\psi_{\text {is }}=\mathrm{f}(\Phi)$ and this is valid for any speed.

Figure 3 shows data published by Broichhausen (1994) with lines for $\Psi$ plotted against flow coefficient $\Phi$. The lower the speed, the more the $\Psi-\Phi$ correlation is a straight line.

\section{Efficiency}

Figure 4 shows the efficiency values corresponding to Figure 3. For the relative speed values $0.4,0.6$ and 0.8 the efficiency lines collapse in the region where flow coefficients are less than $\Phi \approx 1.2$, where the peak efficiency values occur.

Another efficiency correlation originates from theoretical considerations about impulse turbines. In such a turbine the inlet guide vane works like a nozzle which produces the jet velocity $\mathrm{V}_{1}$. There is no velocity change in the rotor of an impulse turbine $\left(\mathrm{W}_{2}=\mathrm{W}_{1}\right)$ as can be seen in Figure 5. Maximum efficiency is achieved when the direction of the absolute velocity $V_{2}$ at the turbine exit is axial. The ratio of $U / V_{1}$ for optimum efficiency is approximately 0.47 .
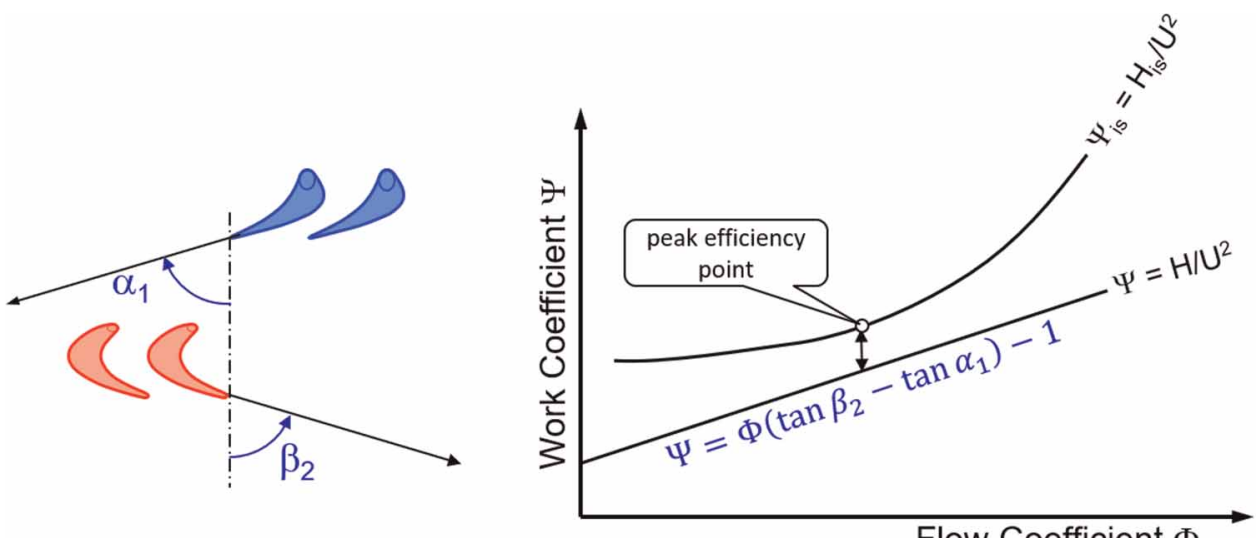

Flow Coefficient $\Phi$

Figure 2. Peak efficiency point of the $\boldsymbol{\psi}-\boldsymbol{\Phi}$ correlation. 


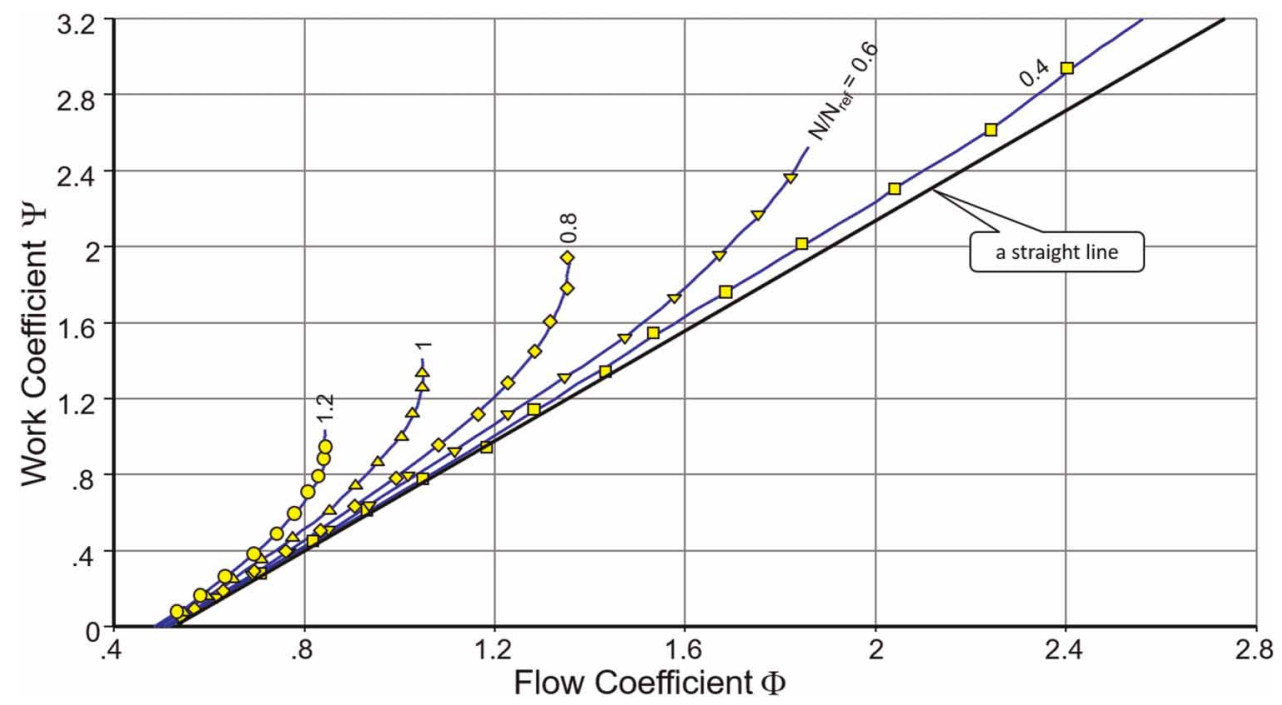

Figure 3. $\Psi-\Phi$ correlations from a turbine.

Experience from working with the maps of many single- and multi-stage turbines has shown that efficiency generally correlates well with the speed/jet-velocity ratio. Figure 6 demonstrates this for the same turbine as used for Figure 3.

Note that Figure 6 does not employ the absolute circumferential speed $U-$ it uses relative speed $N / N_{\text {ref. }}$ The $\mathrm{x}$-axis numbers in Figure 6 therefore differ in magnitude from the value shown in Figure 5.

The correlations of efficiency with flow coefficient and speed ratio are useful only in the region with positive effective work $\mathrm{H}_{\text {eff. }}$ Efficiency is zero if effective work is zero and drops to minus infinity when pressure ratio is 1 , see Figure 7.

\section{Torque}

Turbine power can be expressed as the product of flow and specific work as well as the product of angular speed and torque:

$$
P W=m * H=\omega * \operatorname{Tr} q
$$

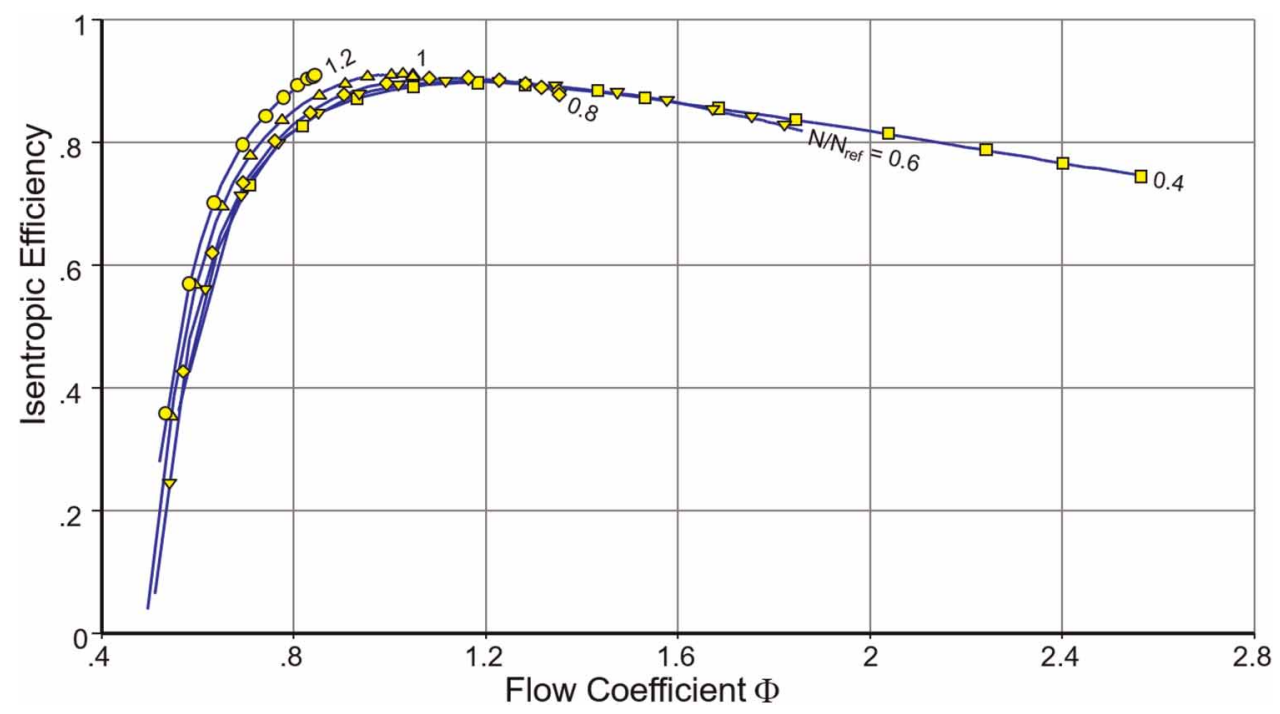

Figure 4. Efficiency corresponding to Figure 3. 

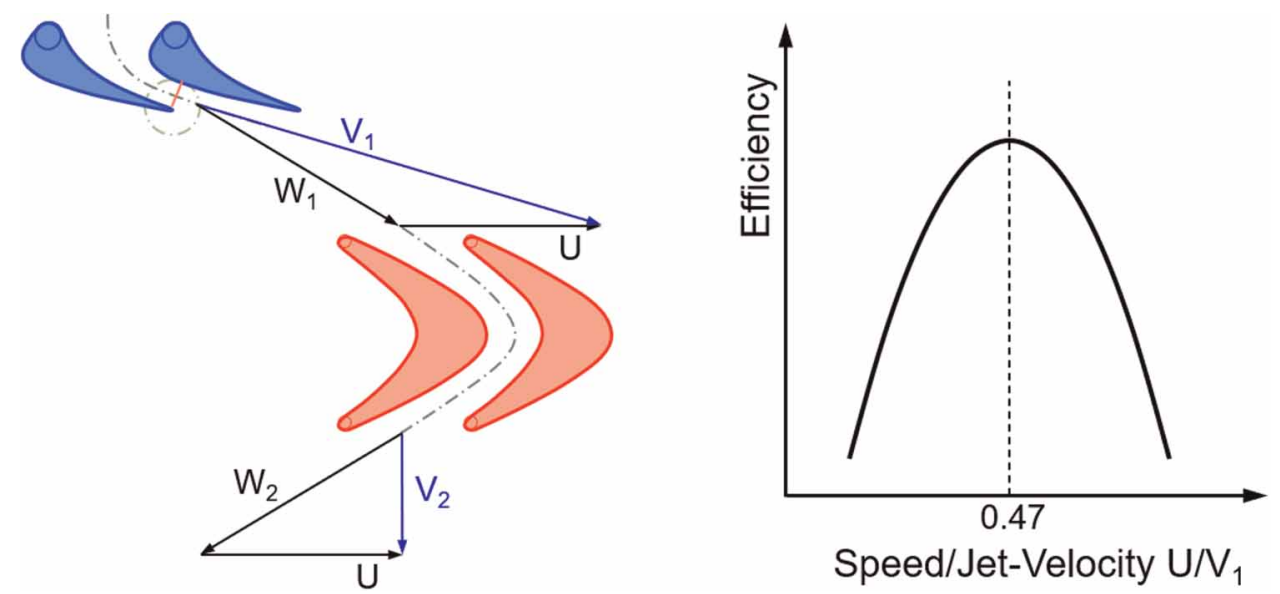

Figure 5. Impulse turbine.

Rearrangement and insertion of Equation 1 yields

$$
\frac{\operatorname{Trq}}{m^{2}}=c_{2} * \frac{H}{U^{2}} * \frac{U}{m}=c_{2} * \frac{c_{1} * \Phi-1}{\Phi}=c_{1} * c_{2}-c_{2} * \frac{1}{\Phi}
$$

This equation is valid where flow velocity $\mathrm{V}_{\mathrm{ax}}$ is proportional to mass flow $\mathrm{m}$, in the incompressible flow region. Under this condition, $\mathrm{Trq} / \mathrm{m}^{2}$ is a linear function of $1 / \Phi$ and $\mathrm{Trq} / \mathrm{m}$ is - for a given circumferential speed $\mathrm{U}-$ a linear function of $\mathrm{m}$ :

$$
\frac{\operatorname{Trq}}{m}=c_{1} * c_{2} * m-c_{2} * U
$$

Figure 8 shows that Equation 4 is in line with measured data in the low mass flow parts of the speed lines. The dashed lines are exactly parallel, the horizontal distance between the lines is independent of speed. This is remarkable because the data are from a three-stage turbine while Equation 4 has been derived for a single stage machine.

In addition to the scale for flow, Figure 8 shows a scale for Mach number. The torque/flow lines bend upwards at Mach numbers higher than $0.4 \ldots 0.45$, which is due to compressibility effects.

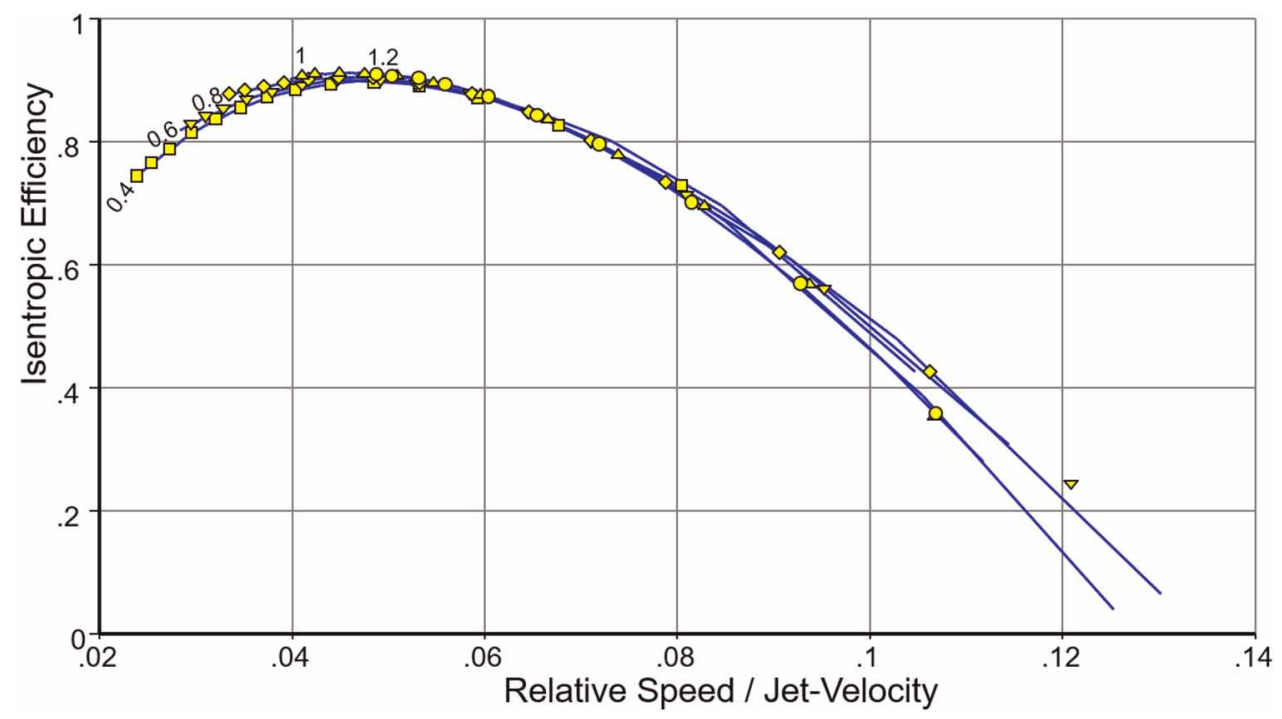

Figure 6. Efficiency $=f\left(N / V_{j e t}\right)$. 


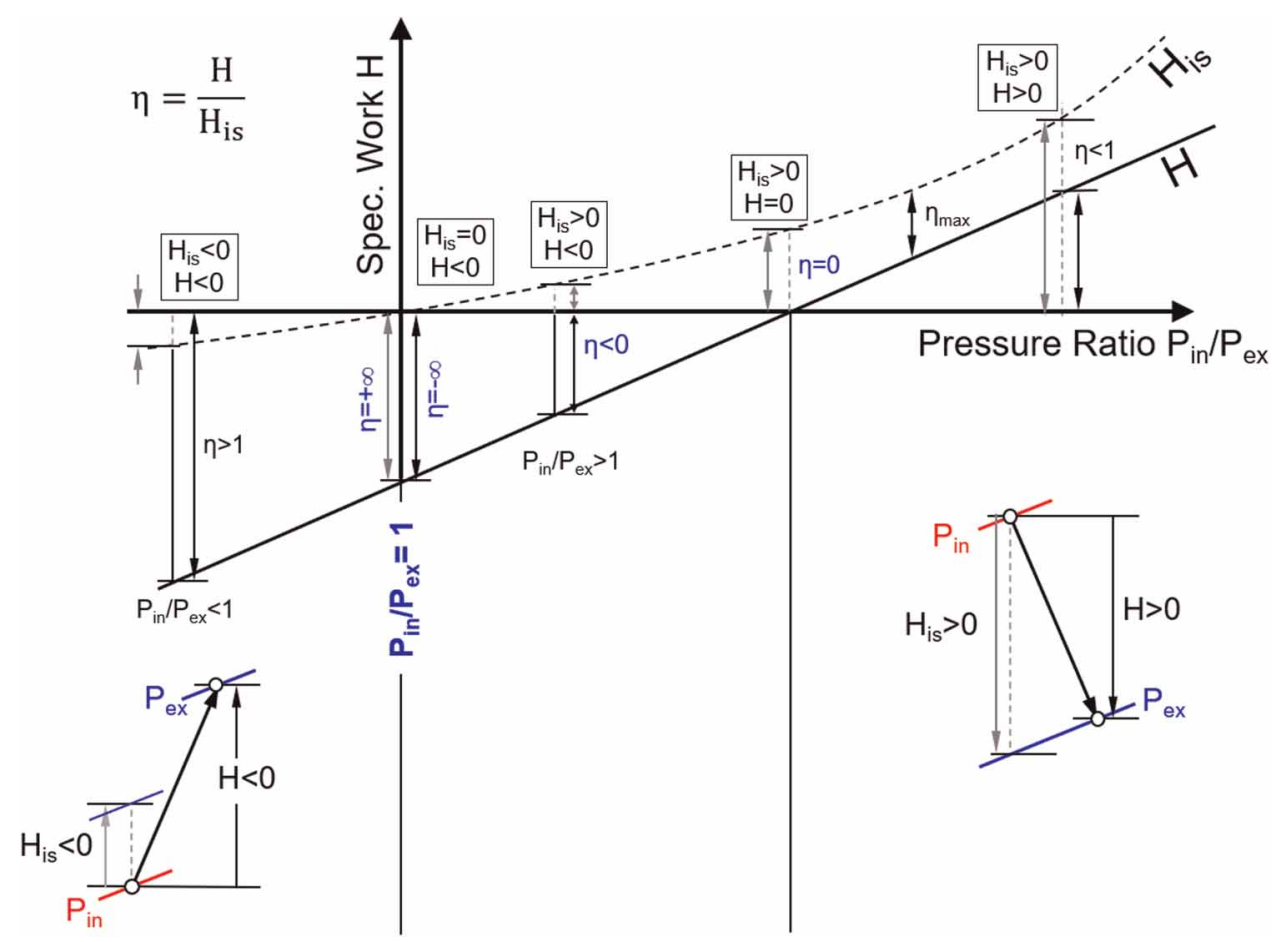

Figure 7. Efficiency around pressure ratio 1.

\section{The zero-speed line}

For a locked rotor, the turbine may be considered as a pipe with restrictions. Total temperature is constant because no work is transferred. Total pressure decreases from the inlet to the exit of the turbine. For incompressible flow, the zero-speed line - i.e. the pressure ratio $=\mathrm{f}(\mathrm{flow})$ correlation - is a parabola.

The locked rotor changes the direction of the fluid and downstream of the rotor this is determined by the rotor blade exit geometry. Torque is proportional to the force in the circumferential direction which is exerted by the fluid on the locked rotor. Equation 4 is also valid for the locked rotor.

\section{The zero-flow line}

Reverse flow never happens in turbines during starting and windmilling simulations. The zero-flow line is a lower pressure ratio limit for the turbine map extension discussed. The velocity triangles yield interesting insights

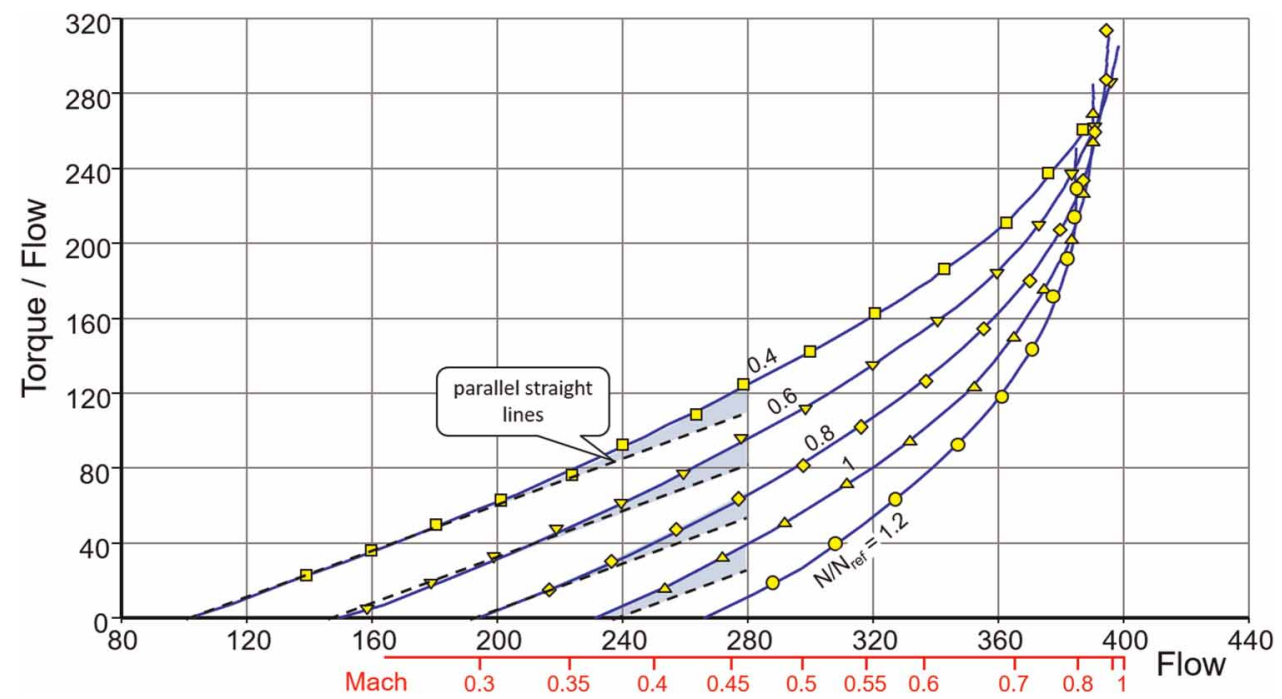

Figure 8. Torque $/$ Flow $=\mathrm{f}($ Flow $)$. 

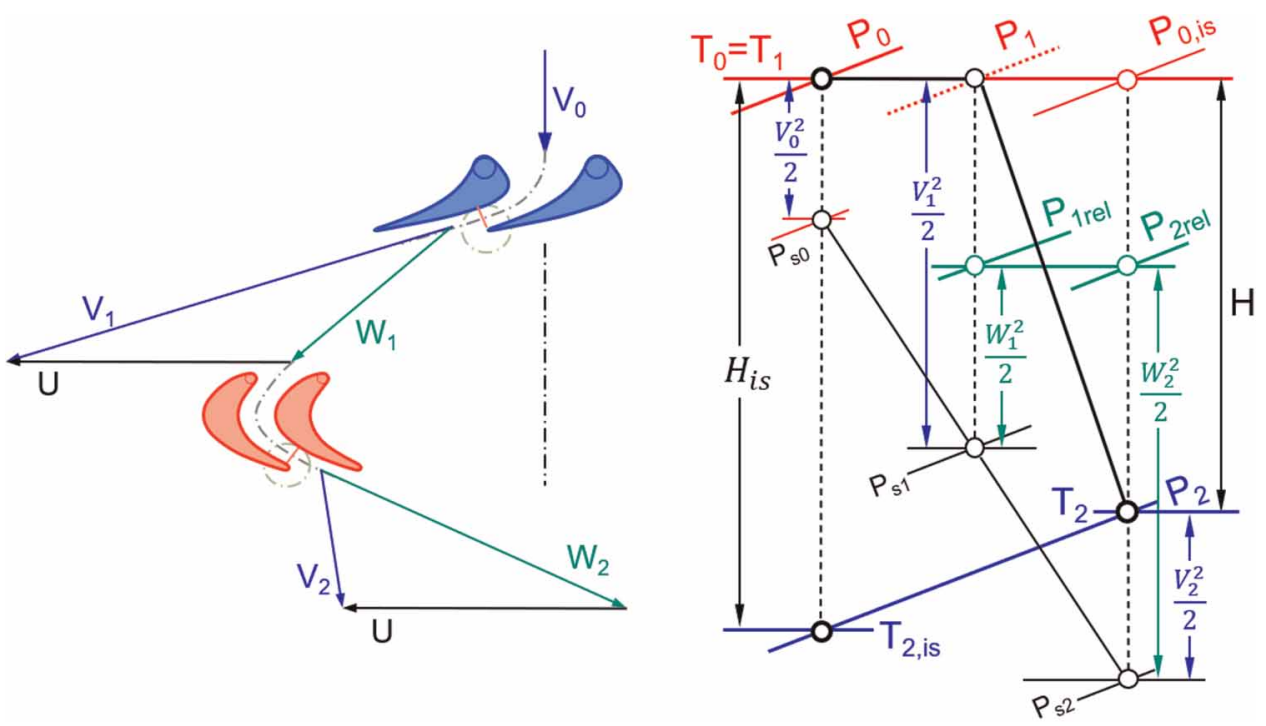

Figure 9. Velocity triangles and enthalpy-entropy diagram, turbine design point.

about operation at zero flow. Figure 9 shows how the design point velocity triangles and the enthalpy-entropy diagram look typically.

If the mass flow is reduced at the same speed to very low values and finally to zero, then the incidence to the rotor becomes highly negative, see Figure 10.

The enthalpy-entropy diagrams for the two low mass flow velocity triangles are shown in Figure 11. From the diagram on the right one can conclude that for the zero-flow case, the effective specific work $\mathrm{H}_{\text {eff }}$ is twice as big as the isentropic specific work $\mathrm{H}_{\text {is }}$ since both $\mathrm{W}_{1}$ and $\mathrm{V}_{2}$ are equal to circumferential speed $\mathrm{U}$.

Corrected isentropic work $\mathrm{H}_{\mathrm{is}} / \mathrm{T}_{1}$ is proportional to corrected speed squared:

$$
\frac{H_{i s}}{T_{1}} \propto \frac{U^{2}}{T_{1}} \propto\left(\frac{N}{\sqrt{T_{1}}}\right)^{2}
$$

$H_{\text {is }} / T_{1}$ relates to pressure ratio:

$$
\frac{H_{i s}}{T_{1}}=c_{p} \frac{T_{2, i s}-T_{1}}{T_{1}}=c_{p}\left[\left(\frac{P_{2}}{P_{1}}\right)^{((\gamma-1) / \gamma)}-1\right]
$$

Thus, pressure ratio relates to corrected speed:

$$
\left(\frac{P_{2}}{P_{1}}\right)^{((\gamma-1) / \gamma)}-1=\operatorname{const}\left(\frac{N}{\sqrt{T_{1}}}\right)^{2}
$$

\section{low mass flow}

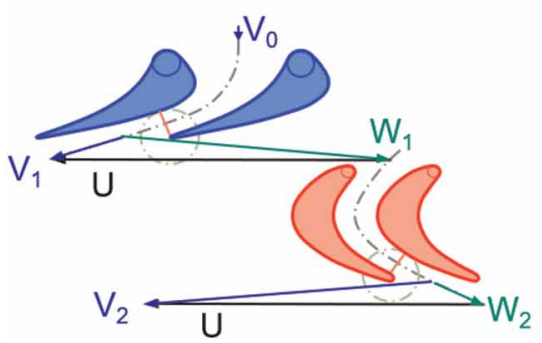

mass flow $<\varepsilon$

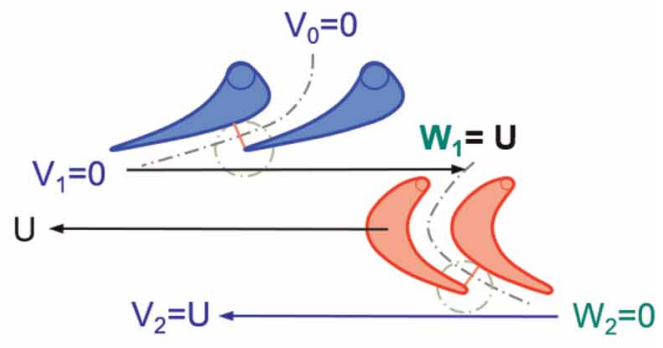

Figure 10. Velocity triangles for low mass flow and mass flow $<\varepsilon$. 


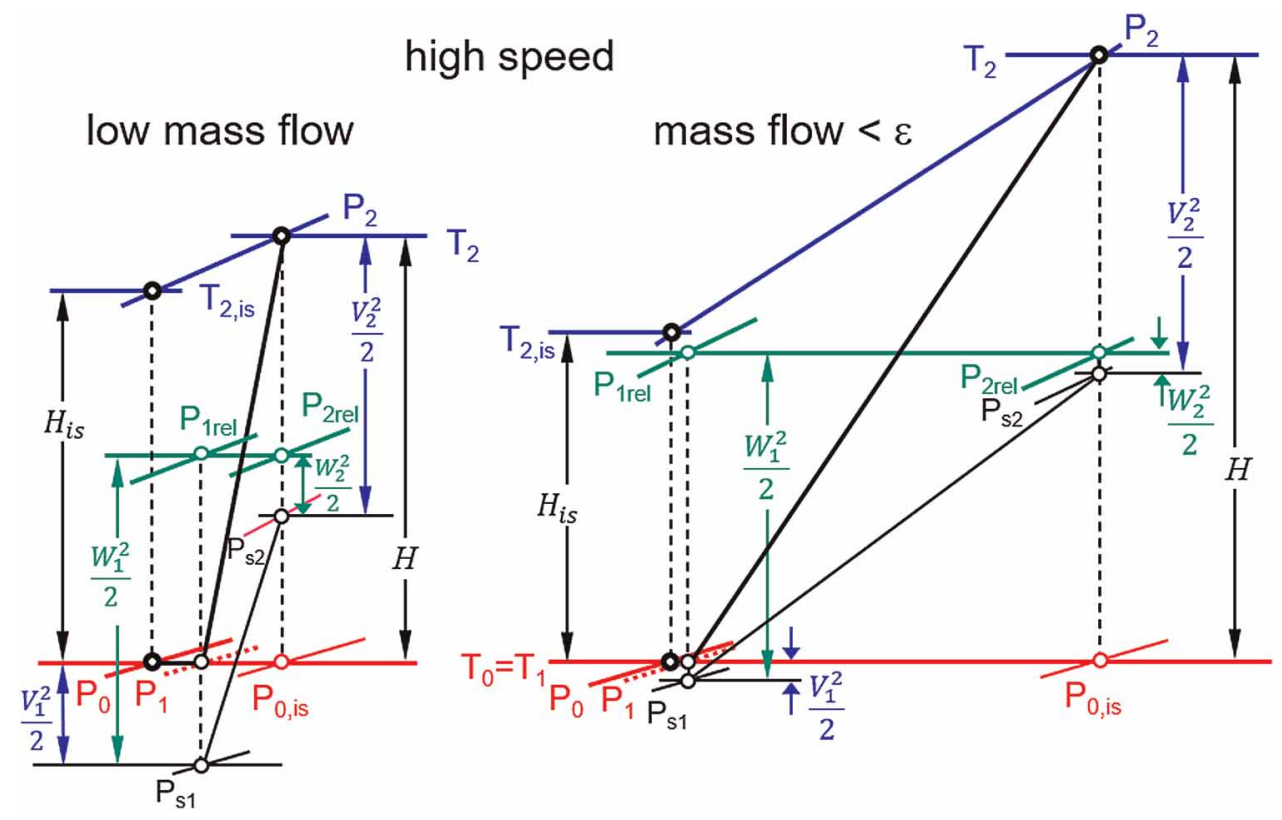

Figure 11. Enthalpy-entropy diagrams corresponding to Figure 10.

Relating the true corrected speed to a reference value makes it easy to determine the constant in this equation because then the speed term equals unity. The difference between specific enthalpy for the temperatures $T_{2, \text { is }}$ and $\mathrm{T}_{1}$ for zero flow is $\mathrm{W}_{1}^{2} / 2$ as the right part of Figure 11 shows.

Since $\mathrm{W}_{1}$ equals $\mathrm{U}$ (Figure 10) it holds that

$$
\left(\frac{P_{2}}{P_{1}}\right)^{((\gamma-1) / \gamma)}=\frac{T_{2 i s}}{T_{1}}=1+\frac{\gamma-1}{2} M_{U}^{2}
$$

The circumferential Mach number $\mathrm{M}_{\mathrm{U} \text {,ref }}$ at the map reference point needs to be estimated. The constant in Equation 7 follows from Equation 9:

$$
\text { const }=\frac{\gamma-1}{2} M_{U, \text { ref }}^{2}
$$

Pressure ratio for any other corrected speed follows from

$$
\frac{P_{2}}{P_{1}}=\left[1+\operatorname{const}\left(\frac{N / \sqrt{T}}{(N / \sqrt{T})_{\text {ref }}}\right)^{2}\right]^{(\gamma /(\gamma-1))}
$$

\section{Flow at pressure ratio 1}

Figure 12 shows the velocity triangles and the enthalpy - entropy diagram for pressure ratio 1 . The rotor entry triangle is symmetrical which makes the total temperature in the relative system $T_{1 \text {,rel }}$ equal to the inlet temperature $T_{1}$. The total pressure losses of the inlet guide vane $\mathrm{P}_{0}-\mathrm{P}_{1 \text {,rel }}$ are compensated by the rotor, which works as a compressor.

The shape of the velocity triangles remains the same when spool speed changes, the triangles remain similar. All enthalpy differences change in proportion to circumferential speed squared and mass flow changes in proportion to circumferential speed. Therefore, the pressure ratio 1 line is linear in a plot of flow vs. speed. 

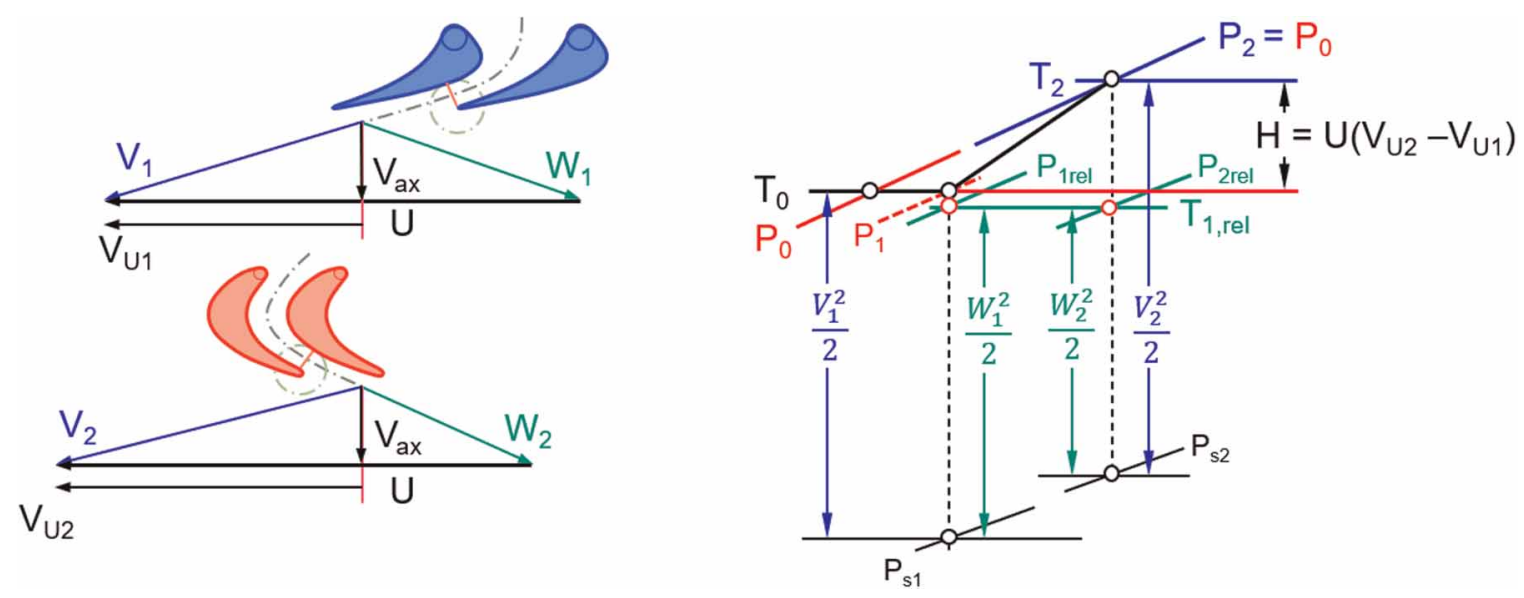

Figure 12. Pressure ratio 1.

\section{Application}

The turbine map extension method described here is implemented in the most recent version of the program Smooth T. This software is a specialized plotting routine which helps a performance engineer generate smooth and meaningful lines through a cloud of measured or calculated data points. Many graphs show the measured data together with the lines in figures with physically meaningful parameters to allow checking whether the result makes sense or not.

The efficiency contour lines in a pressure ratio - speed plot for a turbine define a landscape with a broad peak region at high speed (Figure 13). This high efficiency region becomes smaller in the mid speed range and deforms to a narrow ridge at low speed. Small differences in pressure ratio coincide with big changes in efficiency in this map region. Capturing the details of the efficiency ridge at low speed accurately would require a huge number of equally distributed pressure ratio grid points. Using a rectangular grid marked with the grey circles in Figure 13 would lead to severe accuracy problems in the low speed area. Moreover, we would have to store much useless data - especially in the region of high pressure ratios and low speed. We never need to know the turbine performance in that part of the map when we simulate standard gas turbine performance.

We can achieve high accuracy with a minimum number of grid points if we focus on the region of interest, which is the peak efficiency zone. The blue circles in in Figure 13 are distributed in such a way that we get adequate accuracy for any point of interest in the map. The blue circles are at the crossing between the speed lines with so-called ß-lines which serve as auxiliary coordinates for reading data from the map. (Kurzke and Halliwell 2018).

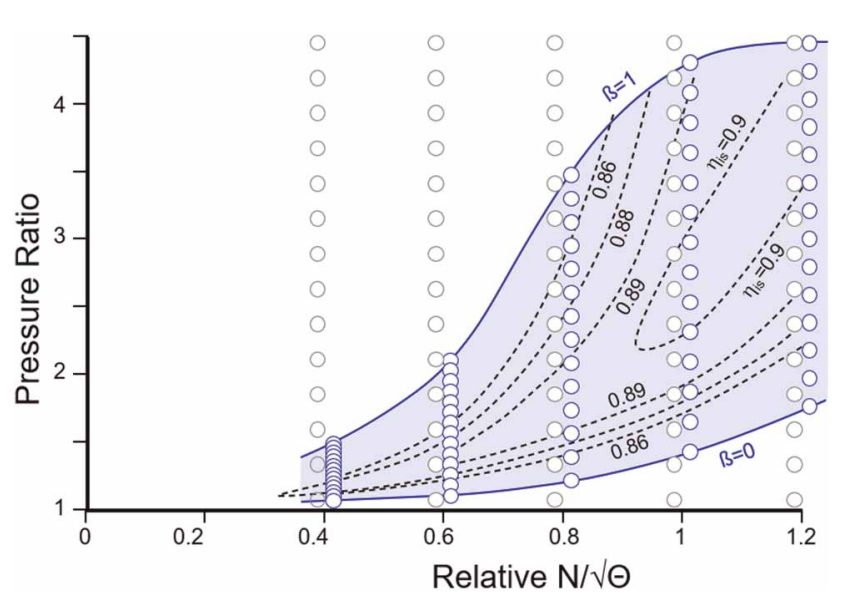

Figure 13. The boundaries of the $ß$-line grid. 


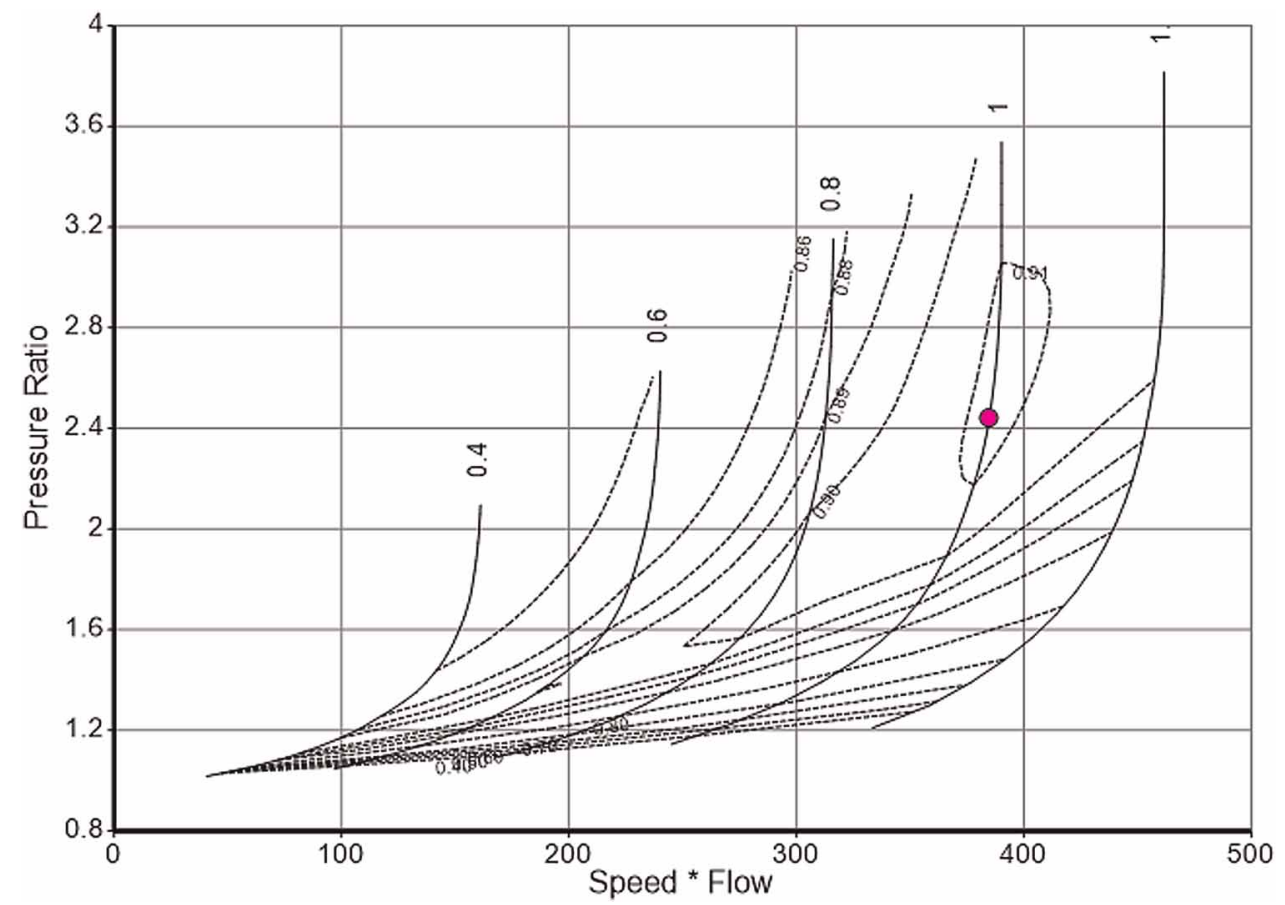

Figure 14. Baseline map.

\section{Baseline map}

The turbine map shown previously in Figures 3, 4, 6 and 8 serves to illustrate the map extension method. This map is from a three-stage low pressure turbine designed for a business jet engine.

The map as shown in Figure 14 has been created using 30 ß-lines with the standard procedure described in the Smooth T manual. The $ß$-line grid encloses all the given data points. The $ß$-numbers (between 0 and 1 ) have no physical meaning. The map reference point is properly placed at the peak efficiency location of the speed line 1.

\section{Extension to zero flow}

A new $\beta$-line grid is required for extending the map to zero flow. The upper $\beta$-line $(B=1)$ remains unchanged, the lower $\beta$-line, however, will now get a physical meaning: it will represent zero-flow. This line passes through

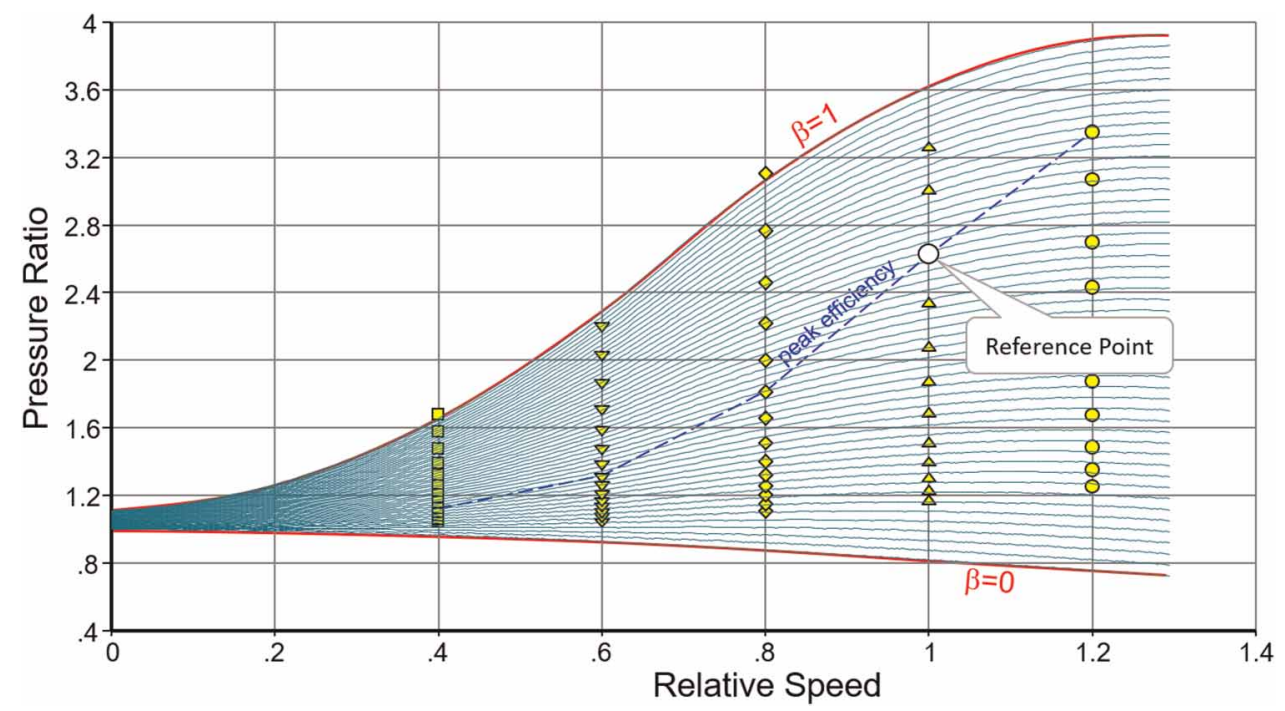

Figure 15. Revised ß-line grid. 


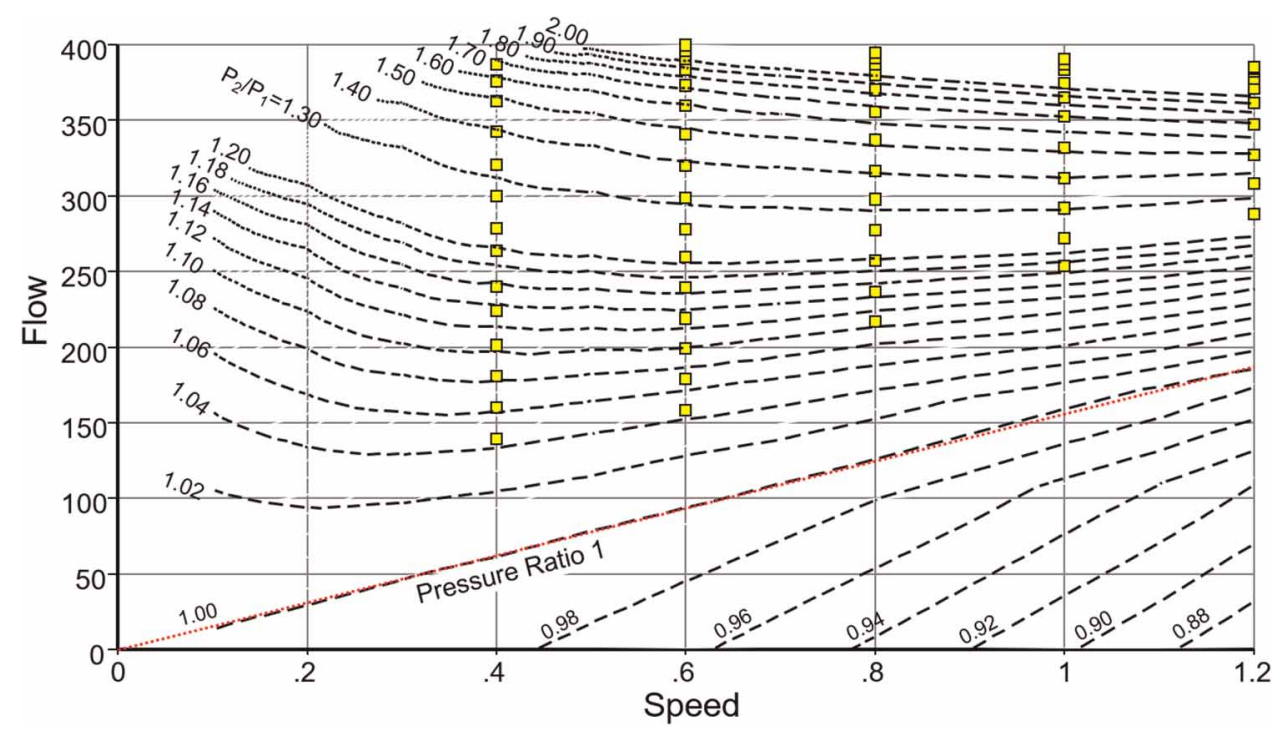

Figure 16. Constant pressure ratio lines in the plot of flow $=f(s p e e d)$.

the origin (relative speed $=0$, pressure ratio $=1$ ) and bends downwards when speed increases. The shape of the zero-flow line is given by Equation 10 and is defined implicitly by the circumferential Mach number $M_{U}$ for relative speed 1.

Note that the number of $ß$-lines needs to be increased because the pressure ratio range is bigger. 50 ß-lines have been used in Figure 15.

Start the map extension with a guess for the $\beta=0$ line by choosing $M_{U}=0.5$, for example. All the extended flow lines begin with mass flow zero on the $ß=0$ line and approach the measured data points smoothly.

Modify the assumption for $\mathrm{M}_{\mathrm{U}}$ if the lines flow $=\mathrm{f}$ (pressure ratio) do not merge smoothly with the part of the line which is defined by measured data. Special attention should be paid to comparing the shape of the line for the lowest speed with that for zero speed.

The discussion of Figure 12 lead to the conclusion that in a plot flow $=\mathrm{f}(\mathrm{speed})$ with contour lines for pressure ratio, the line 1.0 must be a straight line. As Figure 16 shows, this is true.

Also check the correlation between isentropic work coefficient and flow coefficient (Figure 17). All speed lines must collapse in the low flow coefficient region.

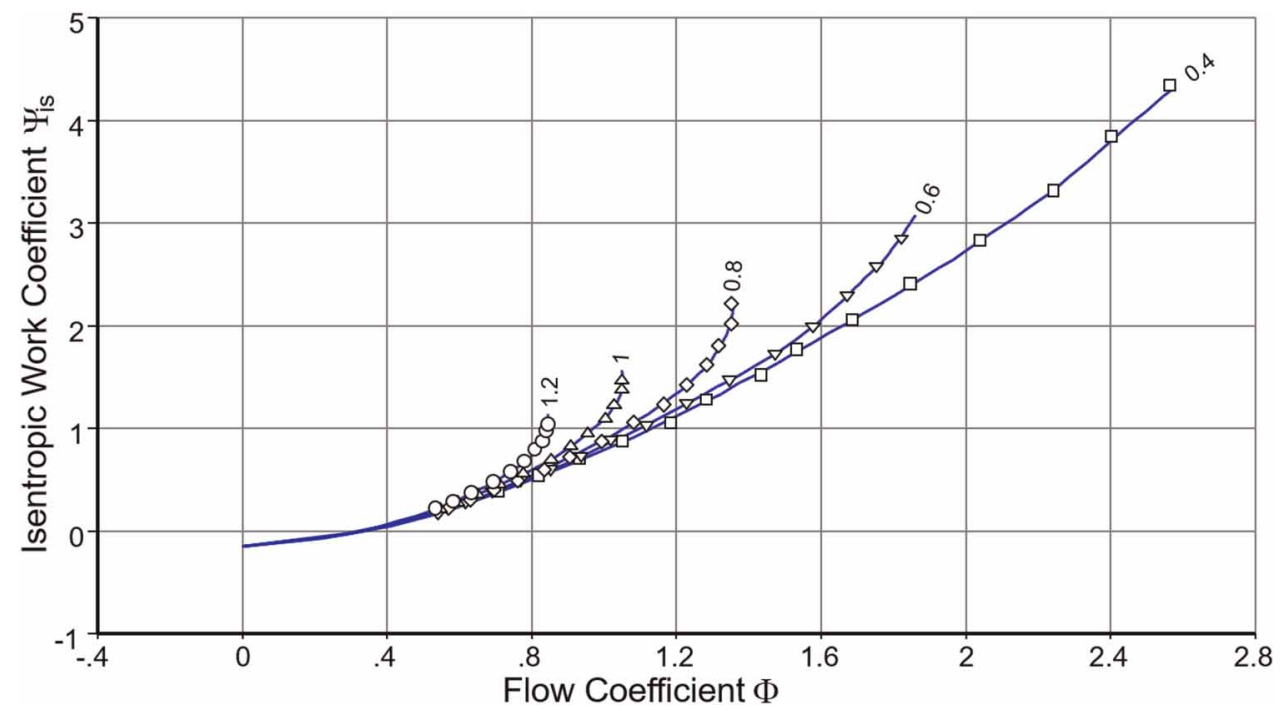

Figure 17. $\Psi_{\text {is }}=f(\Phi)$. 


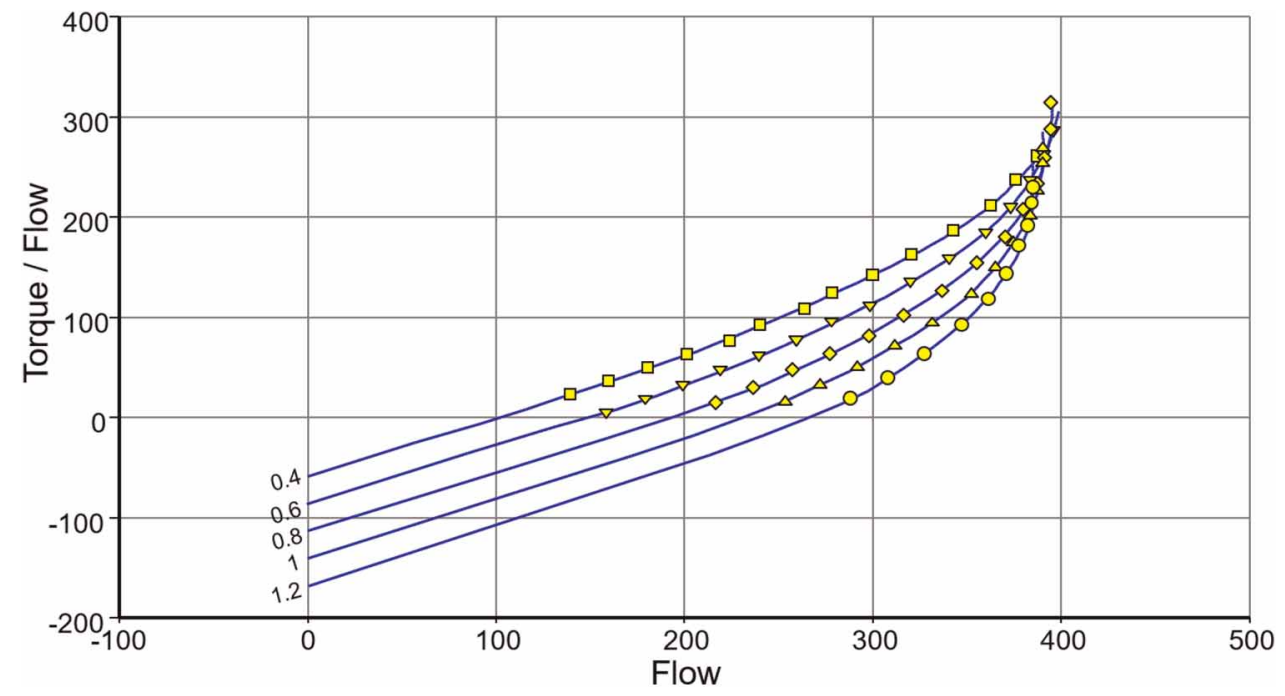

Figure 18. Map extension to low flow.

Next check if the torque/flow $=\mathrm{f}($ flow $)$ lines are straight in the region of low flow. That corresponds to low Mach number and is where incompressible flow theory is applicable. Figure 18 shows how the extended map looks now.

Equation 1 indicates that in incompressible flow the correlation between work and flow coefficients is linear and all lines collapse. Figure 19 shows that this is truly the case in our map example.

\section{Extension to low speed}

Extending the map to low speed uses the same ß-line grid as before. Add one speed line after the other and adapt the mass flow line first in such a way that it matches Figure 20 reasonably well.

Next check the torque/flow $=\mathrm{f}($ flow $)$ plot - in the beginning it will probably not look good. Correct the torque/flow lines in such a way that efficiency lines up with the other data in the plot efficiency $=\mathrm{f}(\mathrm{speed} / \mathrm{jet}$ velocity), as in Figure 6.

If it is not feasible to get both efficiency and torque/flow lines right, then the form of the function flow $=\mathrm{f}$ (pressure ratio) needs to be modified. Go back and modify the flow lines in such a way that the torque/flow lines have the desired shape.

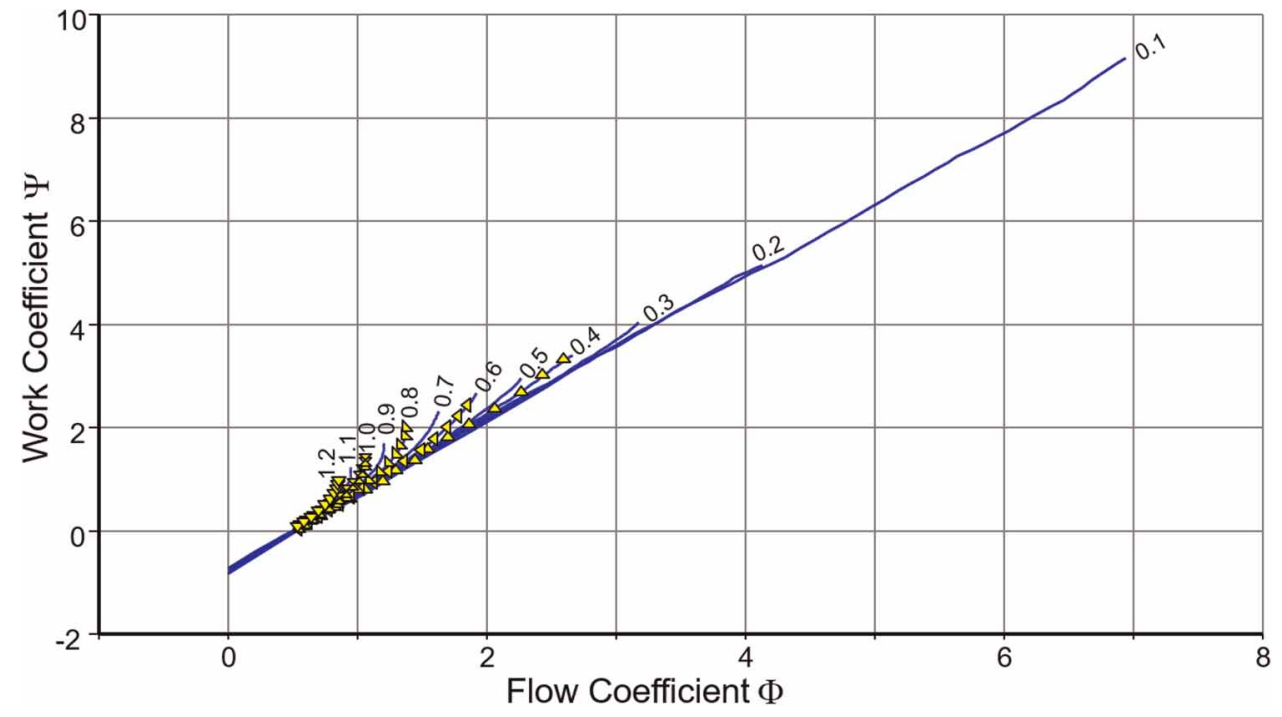

Figure 19. $\Psi=f(\Phi)$ with added speed lines. 


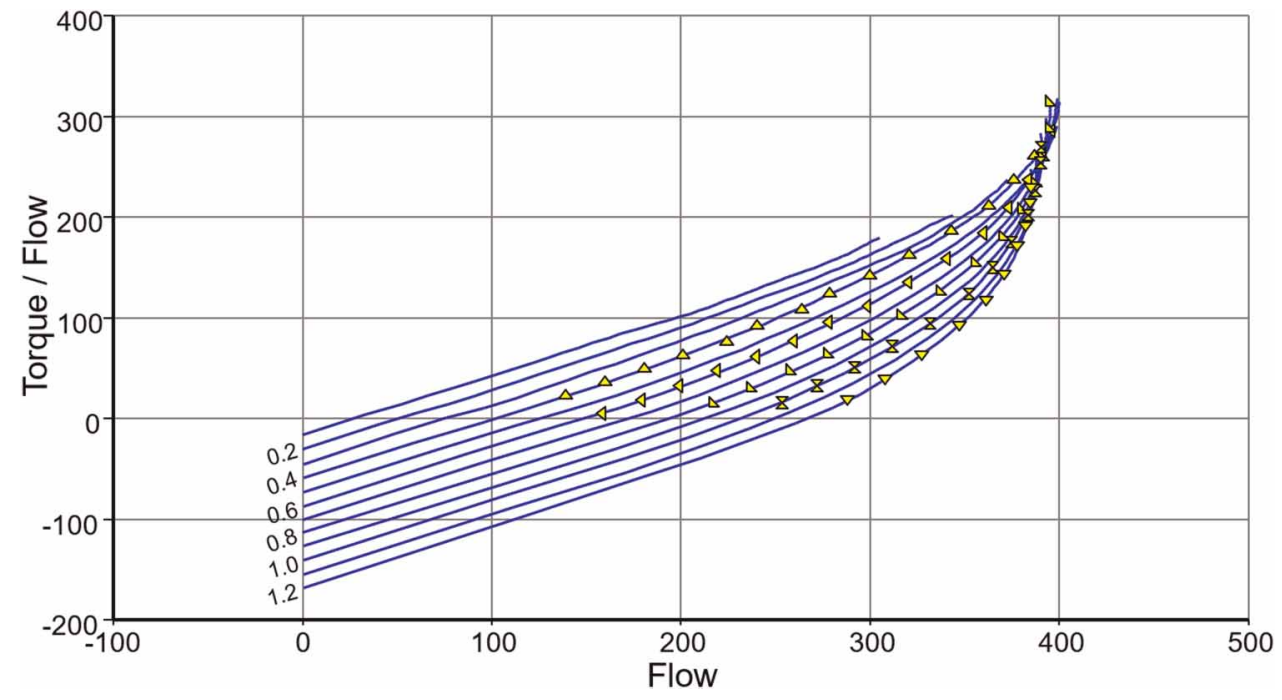

Figure 20. Torque/Flow $=\mathrm{f}($ Flow $)$

To get all the correlations right requires only a few iterations. The final result of the map extension process is shown in Figures 20, 21 and 22.

\section{Concluding remarks}

The turbine map extension towards low mass flow is based on incompressible flow theory. The lower limit of the map is the zero-flow line - negative flow will not happen during aircraft engine start and windmilling.

The advantage of the current method over using map calculation programs is that no geometry information is needed. The accuracy of the result is more than adequate for starting and windmilling performance simulations.

The approach is implemented in the software Smooth $\mathrm{T}$ and has been applied successfully to many maps from the open literature. Starting and windmill relight simulations have been demonstrated with GasTurb. Deviations from full engine test data are expected due to uncertainties in the modeling of oil viscosity effects on gearbox drag and bearing losses. Also, combustor light up and efficiency immediately after ignition are in some degree random effects, and that makes an absolute agreement between model and reality improbable.

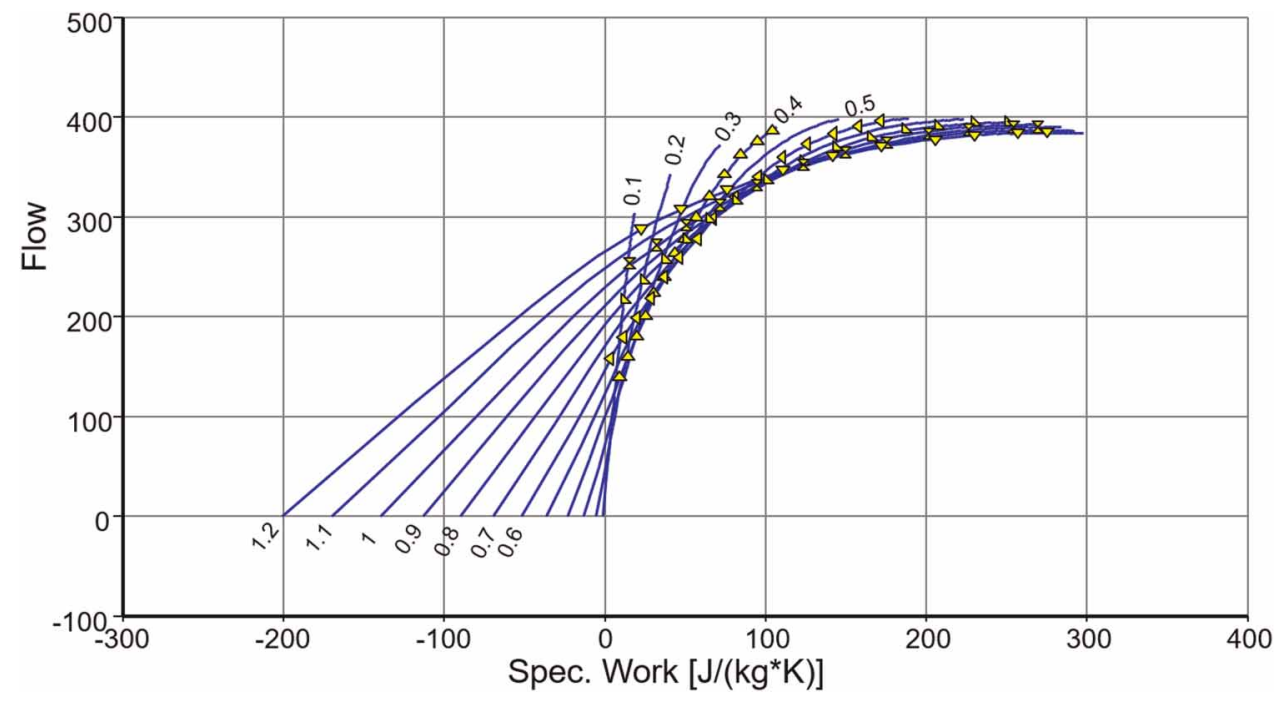

Figure 21. Flow and specific work. 


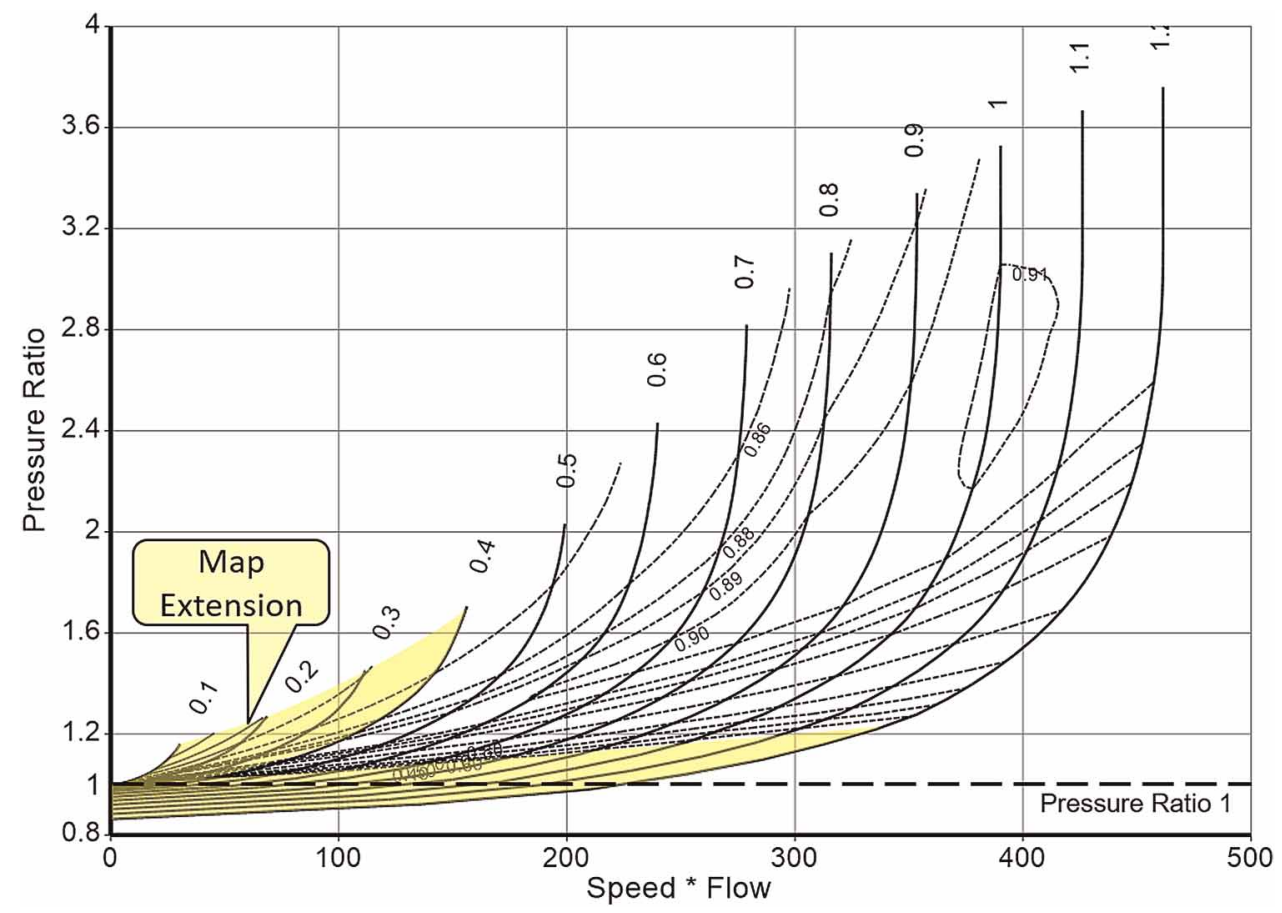

Figure 22. Map with extrapolated and interpolated speed lines.

\section{Nomenclature}

$\begin{array}{ll}\mathrm{c}_{1}, \mathrm{c}_{2}, \ldots & \text { constant values } \\ \mathrm{c}_{\mathrm{P}} & \text { specific heat at constant pressure } \\ \text { eff } & \text { effective } \\ \mathrm{H} & \text { specific work } \\ \text { is } & \text { isentropic } \\ \mathrm{m} & \text { (corrected) mass flow } \\ \mathrm{M} & \text { Mach number } \\ \mathrm{M}_{\mathrm{U}} & \text { circumferential Mach number } \\ \mathrm{N} & \text { rotational speed } \\ \mathrm{P} & \text { total pressure } \\ \mathrm{P}_{\mathrm{s}} & \text { static pressure } \\ \mathrm{S} & \text { specific entropy } \\ \mathrm{T} & \text { total temperature } \\ \mathrm{Trq} & \text { torque } \\ \mathrm{U} & \text { circumferential speed } \\ \mathrm{V} & \text { absolute velocity } \\ \mathrm{V}_{\text {ax }} & \text { axial component of } \mathrm{V} \\ \mathrm{V}_{\mathrm{U}} & \text { circumferential component of } \mathrm{V} \\ \mathrm{W} & \text { relative velocity } \\ \mathrm{W}_{\mathrm{U}} & \text { circumferential component of } \mathrm{W} \\ \alpha_{1} & \text { stator exit flow angle } \\ \beta_{2} & \text { rotor blade exit flow angle } \\ \beta & \text { map coordinate } \\ \gamma & \text { isentropic exponent } \\ \eta & \text { efficiency } \\ \Phi & \text { flow coefficient } \mathrm{V}_{\text {ax }} / \mathrm{U} \\ \Psi & \text { work coefficient } \mathrm{H} / \mathrm{U}^{2} \\ \Psi_{\text {is }} & \text { isentropic work coefficient } \mathrm{H}_{\text {is }} / \mathrm{U}^{2} \\ \Pi & \text { pressure ratio } \\ \omega & \text { angular speed } \\ & \end{array}$




\section{Acknowledgments}

Many thanks to Daniel Weintraub from the GasTurb team in Aachen, Robert Hill and Ian Halliwell for their valuable comments.

\section{Competing interests}

Joachim Kurzke has no conflict of interest.

\section{References}

Broichhausen K. (1994) Aerodynamic Design of Turbomachinery Components - CFD in Complex Systems. in AGARD Lecture Series 195. Turbomachinery Design Using CFD.

Kurzke J., and Halliwell I. (2018) Propulsion and Power - An Exploration of Gas Turbine Performance Modeling. Springer International Publishing AG, Cham, Switzerland. ISBN 978-3-319-75977-7, 2018. 